\title{
Detection of early lung impairment with aerosol bolus dispersion
}

\author{
P. Brand*, T. Tuch*, O. Manuwald**, W. Bischof**, J. Heinrich+, \\ H.E. Wichmann+, T. Beinert*, J. Heyder*
}

Detection of early lung impairment with aerosol bolus dispersion. P. Brand, T. Tuch, O. Manuwald, W. Bischof, J. Heinrich, H.E. Wichmann, T. Beinert, J. Heyder. CERJ Journals Ltd 1994.

ABSTRACT: The broadening of inhaled aerosol boluses (aerosol bolus dispersion) during respiration provides a noninvasive measure of convective gas mixing in the lungs. In this study, the sensitivity and specificity of this technique for the diagnosis of early lung impairment due to cigarette smoking was evaluated.

Two hundred and sixteen randomly selected subjects (126 smokers and 90 nonsmokers) were investigated with aerosol dispersion in comparison to conventional lung function tests. The cumulative cigarette consumption of the subjects was quantified by "pack-years" (PY). Smokers were classified into the following groups: $0<\mathrm{PY} \leq 10 ; 10<\mathrm{PY} \leq 20 ; 20<\mathrm{PY} \leq 30$; and $\mathrm{PY}>30$.

Forced expiratory volume in one second $\left(\mathrm{FEV}_{1}\right)$, maximal expiratory flow at 25 , 50 and $75 \%$ vital capacity $\left(\mathrm{MEF}_{25}, \mathrm{MEF}_{50}\right.$ and $\left.\mathrm{MEF}_{75}\right)$ decreased significantly with increasing cigarette consumption. In comparison to nonsmokers, $\mathrm{FEV}_{1}$ was significantly reduced in smokers of $10<\mathrm{PY} \leq \mathbf{3 0}$, and $\mathrm{MEF}_{75}$ was significantly reduced in smokers of PY >20. Aerosol bolus dispersion increased with increasing PY. For all groups of smokers, even those with PY $<10$, bolus dispersion was significantly increased in comparison to lifelong nonsmokers, indicating alterations in convective gas mixing in the lungs. Calculation of receiver operating characteristics for the lung function parameters under consideration showed that bolus dispersion has a higher sensitivity and specificity than conventional lung function parameters.

Hence, the aerosol bolus dispersion test could be a promising epidemiological tool to study early abnormalities in intrapulmonary gas mixing due to environmental factors.

Eur Respir J., 1994, 7, 1830-1838.
*GSF-Forschungszentrum für Umwelt und Gesundheit, Projekt Inhalation and +Institut für Epidemiologie, Oberschleißheim, FRG. ** Institut für Allgemeine und Kommunale Hygiene der Medizinischen Hochschule Erfurt, Abt. Umwelthygiene, Erfurt, FRG.

Correspondence: P. Brand

GSF-Forschungszentrum für Umwelt und Gesundheit

Projekt Inhalation

Neuherberg

Postfach 1129

85758 Oberschleißheim

Germany

Keywords: Aerosol bolus dispersion conventional lung function tests

sensitivity

small airway inflammation

smoking

specificity

Received: October 181993

Accepted after revision June 141994
Various severe and epidemiologically important lung diseases originate in the lung periphery [1]. Chronic obstructive pulmonary disease (COPD) and asthma are diseases which are associated with a destruction, obstruction, or inflammation of peripheral airspaces. Unfortunately, conventional tests of lung function, such as spirometry or body-plethysmography, suffer from a lack of sensitivity in detecting such early peripheral lung impairment. Forced expiratory flow rates and total airway resistance reflect properties of the central airways and are almost unaffected by changes in the smaller airways [2]. On the other hand, it has been shown that the regional distribution of inhaled air is altered in smokers with normal spirometry [3]. Therefore, lung function tests which are sensitive for changes in lung ventilation pattern are supposed to be more suitable for the early detection of changes in the lung periphery caused by smoking and, presumably, other exogeneous factors.

The aerosol bolus dispersion technique, applying boluses of submicron aerosol particles as a lung probe, delivers a quantitative measure of convective mixing in the lungs. This technique has been used for diagnostic purposes in several studies $[4,5]$, and has shown interesting capabilities which promise to provide a powerful supplement to conventional lung function tests. It was stated that this technique has higher sensitivity to detect early functional alterations in the lung periphery $[6,7]$. In this paper, data available from a field study with 216 randomly selected subjects, who underwent aerosol dispersion, spirometry and oscillatory airway resistance measurements, were used to determine the sensitivity and specificity of each diagnostic test concerning the detection of early changes in lung function. As a model for lung impairment due to exogenous factors, the smoking history of the subjects was taken into consideration.

\section{Methods}

\section{Aerosol bolus dispersion}

Monodisperse aerosol particles can be considered as a nondiffusing gas [8], and can therefore be used as a tracer 

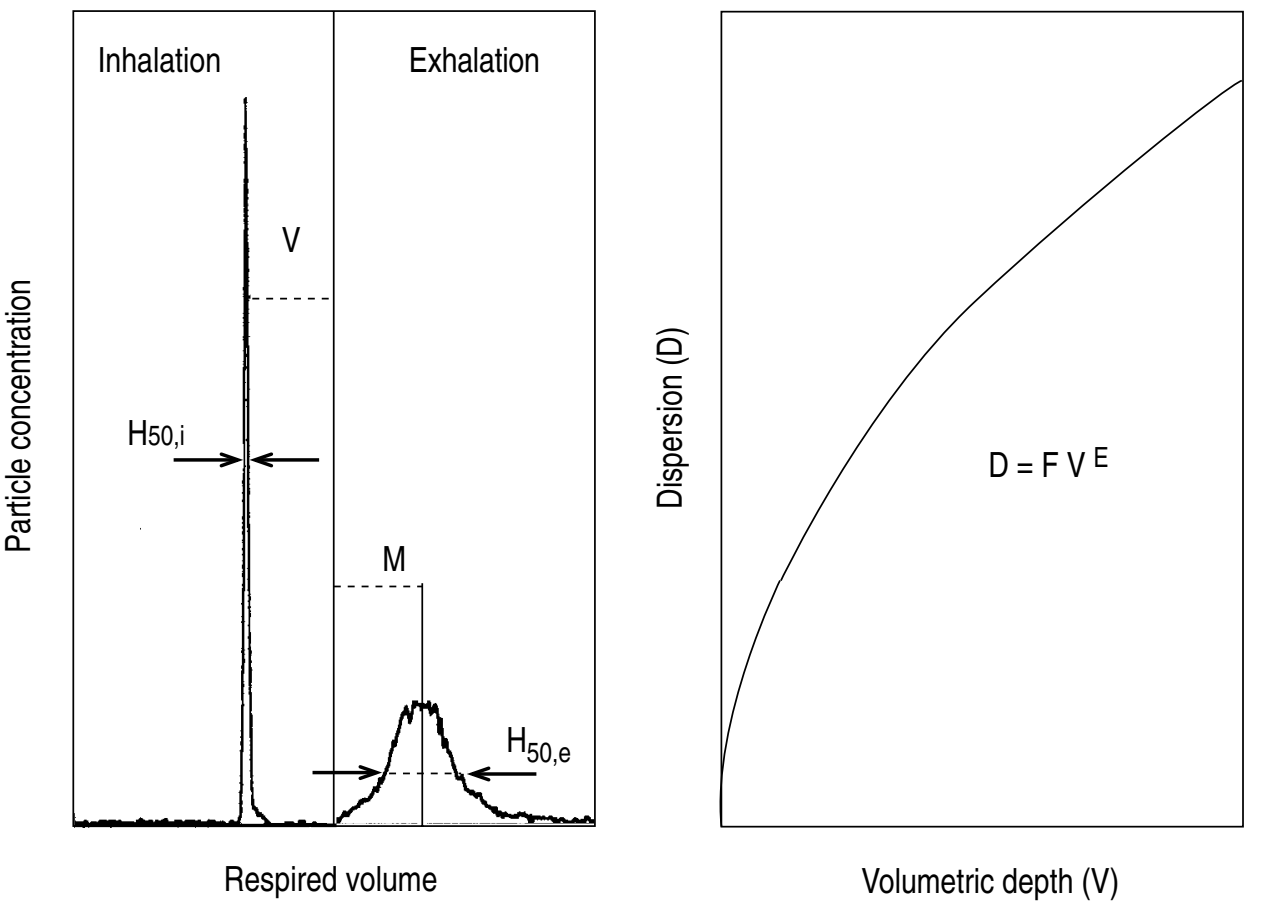

Fig. 1. - Schematic relationship between aerosol particle number concentration and respired volume during the inhalation of an aerosol bolus, and between aerosol bolus dispersion (D) and volumetric lung depth (V) to which the bolus is inhaled. M is the volumetric depth from which the bolus is exhaled. $\mathrm{H}_{50 . \mathrm{i}}$ and $\mathrm{H}_{50 . \mathrm{e}}$ represent the half width of the inhaled and exhaled bolus, respectively.

for convective gas transport. When a small volume (bolus) of such an aerosol is injected into a single breath of clean air, convective gas mixing during respiration will cause particle transport in initially particle free air volumes within the lungs. Upon exhalation the particles are, therefore, distributed over a larger air volume, i.e. the bolus is dispersed $[9,10]$. To characterize the broadness of the inhaled and exhaled aerosol bolus the bolus width at half-maximum particle concentration (halfwidth) $\left(\mathrm{H}_{50, \mathrm{i}}\right.$ and $\mathrm{H}_{50, \mathrm{e}}$, respectively) is calculated (fig. 1). Aerosol dispersion (D) is defined as the increase of the bolus half-width during a respiratory cycle, and can be calculated by [11]:

$$
\mathrm{D}=\left[\mathrm{H}_{50, \mathrm{e}}{ }^{2}-\mathrm{H}_{50, \mathrm{i}}{ }^{2}\right]^{1 / 2}
$$

Dispersion of aerosol boluses is dependent on the volumetric lung depth to which the bolus is penetrating. The volumetric lung depth (V) is determined by the air volume inhaled after bolus application (fig. 1).

The measured relationship between dispersion D and volumetric lung depth $\mathrm{V}$ can be approximated by a power function:

$$
\mathrm{D}=\mathrm{F} \mathrm{VE}^{\mathrm{E}}
$$

The exponent $(\mathrm{E})$, which determines the curvature of the relationship, and the factor $(\mathrm{F})$ of the power function are used, in this paper, to characterize bolus dispersion in lungs. When bolus dispersion is increased, this increase leads to an increase of $\mathrm{E}$ in combination with a decrease of F.

\section{Inhalation apparatus}

The measurement of aerosol bolus dispersion requires: 1) the application of small aerosol volumes into respired clean air; and 2) the measurement of particle number concentration in the air as a function of the respired air volume.

The bolus application is provided by a system of solenoid valves, which allow the inhalation channel to be switched between filtered air and an aerosol supply (fig. 2). By switching the valves automatically using a personal computer, an aerosol bolus with a volume of about $70 \mathrm{~cm}^{3}$ can be injected at various user-defined positions within an inhaled single breath of clean air.

The measurement of the aerosol number concentration and the respired air volume is provided by a device which combines laser aerosol photometry with pneumotachography [12] (fig. 2). This device is located between

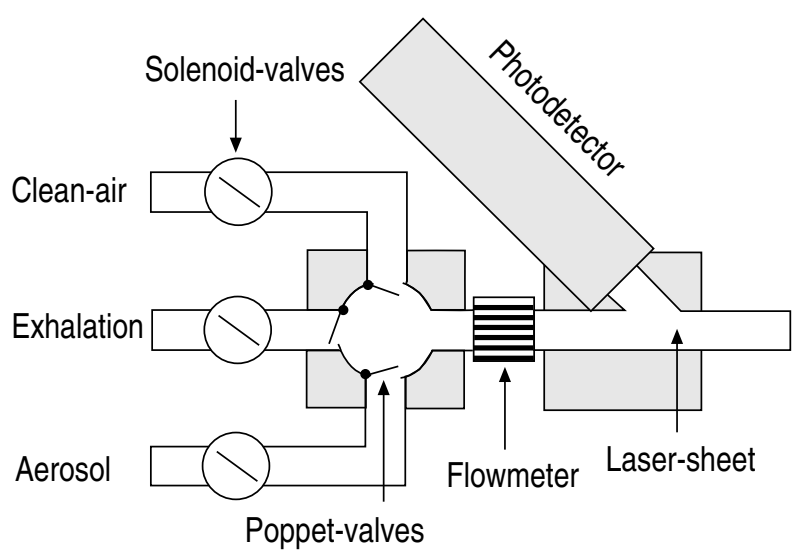

Fig. 2. - Depiction of the aerosol bolus inhalation device. 
the valve system and a mouthpiece. The respired volume is evaluated by on-line integration of the analogous flow signal of a pneumotachograph. To measure the aerosol particle number concentration, the inhaled aerosol is illuminated by the light of a He-Ne laser, and the light scattered by the particles under a scattering angle of $90^{\circ} \mathrm{C}$ is measured by a secondary electron multiplier. The output signal of this multiplier is, in the case of monodisperse aerosol particles, proportional to the aerosol particle number concentration.

\section{Particle production and classification}

Monodisperse di(2-ethylhexyl) sebacate (DEHS) droplets suspended in nitrogen are produced by heterogeneous nucleation of DEHS vapour on $\mathrm{NaCl}$ nuclei in a MAGE aerosol generator (Lavoro e ambiente, Bologna, Italy). The aerosol is then diluted with filtered air to obtain a particle number concentration of about 20,000 particles per $\mathrm{cm}^{3}$. The size of the particles is classified by measuring the terminal settling velocity of the particles in a convection free sedimentation cell [13]. The average settling velocity (mean \pm SD) of the particles throughout the study was $21 \pm 3 \mu \mathrm{m} \cdot \mathrm{s}^{-1}$, representing a mean geometrical particle diameter of $0.8 \pm 0.08 \mu \mathrm{m}$ ).

\section{Spirometry}

Conventional spirometry was performed using commercial devices. Vital capacity (VC), peak expiratory flow $(\mathrm{PEF})$, forced expiratory volume in one second $\left(\mathrm{FEV}_{1}\right)$ and maximal expiratory flows at 25, 50 and $75 \%$ vital capacity (VC) $\left(\mathrm{MEF}_{25}, \mathrm{MEF}_{50}\right.$ and $\left.\mathrm{MEF}_{75}\right)$ were measured with a Jäger-Masterlab (Erich Jäger $\mathrm{GmbH}$, Germany). Total lung capacity (TLC) functional residual capacity (FRC) and residual volume (RV) were measured with a Uniscope-device (Ganshorn Medizin Elektronik GmbH, Germany) by helium dilution using an ultrasonic helium sensor and a gas mixture containing $18 \%$ helium in artificial air. The oscillatory airway resistance $\left(\mathrm{R}_{\mathrm{osc}}\right)$ was measured with LF1 device (Ganshorn Medizin Elektronik $\mathrm{GmbH}$, Germany) with an oscillation frequency of $10 \mathrm{~Hz}$. Relative values of conventional lung function parameters were calculated by normalization to the reference values proposed by the European Community for Coal and Steel [14]. The protocol was approved by the Ethics Committee of the "Medizinische Hochschule Erfurt".

\section{Subjects}

In this study, 700 subjects were randomly selected from the residents register of Erfurt (FRG) and were invited to participate in the study. Two hundred and thirty four subjects from this sample were investigated, yielding 216 valuable data-sets. Anthropometric and lung function data of these subjects are given in table 1. The smoking habits of the subjects were quantified using the cumulative cigarette consumption expressed as pack-years (PY).
One PY represents a daily consumption of 20 cigarettes during one year. We did not distinguish between active smokers and ex-smokers.

\section{Inhalation protocol}

To perform aerosol dispersion measurements, the subject was sitting in an upright position in front of the bolus inhalation device. The subject breathed through a mouthpiece custom-made from a silicone dental compound, which reduced the dead space of the oral cavity. Starting from FRC, the subject inhaled clean-air until the lung volume reached $70 \%$ TLC. During inspiration, the aerosol bolus was applied into volumetric lung depths of $\mathrm{V}=750,550,350,150$, or $100 \mathrm{~cm}^{3}$. Finally, the subject exhaled until the entire aerosol bolus was recovered from the lungs or RV was reached (fig. 3). The breathing manoeuvre was performed at a constant airflow of 250 $\mathrm{cm}^{3} \cdot \mathrm{s}^{-1}$, controlled by the subject by use of a visual flow signal.

\section{Data evaluation}

All statistical calculations were performed using the SAS software package. The significance of differences between group averages were tested using the t-test for independent samples. Analysis of variance was carried out using the procedure for general linear models. To determine the influence of a certain variable, the model was adjusted for all other independent variables included in the model.

The sensitivity and specificity of the various diagnostic tests was quantified by their receiver operating characteristic (ROC) [15]. The aim of this study was to evaluate the capability of various diagnostic tests to detect early lung impairment due to cigarette smoking. Therefore, the sensitivity and specificity of a certain lung function parameter was evaluated from its ability to distinguish between smokers and nonsmokers. For any given threshold value, the sensitivity of a parameter is given by the fraction of true positive, and the specificity by the fraction of true negative classifications of smokers and nonsmokers. The standard deviation of sensitivity is calculated using the equations given by METZ [15]. Varying the threshold level provides the relationship between sensitivity and specificity (ROC-curve) of a certain parameter and allows the intercomparison of different diagnostic tests. The area under this curve represents the probability $\left(\mathrm{p}_{\mathrm{ROC}}\right)$ that a randomly selected pair of smoker and nonsmokers is correctly ranked [16].

\section{Results}

Table 1 shows the mean and standard deviation of anthropometric data, conventional lung function parameters, and bolus dispersion data for all 216 subjects pooled, and separately for males and females. The significance level p quantifies significant differences between males 
Table 1. - Measured lung function parameters for all subjects and group differences between males and females

\begin{tabular}{|c|c|c|c|c|}
\hline Parameter & Pooled & Males & Females & p-value \\
\hline Subject $\mathrm{n}$ & 216 & 106 & 110 & \\
\hline Smokers $\mathrm{n}$ & 126 & 72 & 54 & \\
\hline Age yrs & $43 \pm 12$ & $45 \pm 12$ & $41 \pm 12$ & 0.02 \\
\hline Height $m$ & $1.71 \pm 0.09$ & $1.77 \pm 0.06$ & $1.64 \pm 0.06$ & $<0.001$ \\
\hline PY yrs & $7.6 \pm 11$ & $10.5 \pm 12$ & $4.8 \pm 8$ & $<0.001$ \\
\hline \multirow{2}{*}{$\begin{array}{ll}\mathrm{VC} & l \\
& \text { rel. }\end{array}$} & $4.10 \pm 0.93$ & $4.80 \pm 0.76$ & $3.50 \pm 0.59$ & $<0.001$ \\
\hline & $1.01 \pm 0.12$ & $0.99 \pm 0.12$ & $1.03 \pm 0.12$ & 0.01 \\
\hline \multirow[t]{2}{*}{ TLC } & $6.49 \pm 1.13$ & $7.32 \pm 0.87$ & $5.68 \pm 0.68$ & $<0.001$ \\
\hline & $1.08 \pm 0.11$ & $1.04 \pm 0.11$ & $1.12 \pm 0.11$ & $<0.001$ \\
\hline \multirow[t]{2}{*}{ FRC } & $3.48 \pm 0.78$ & $3.77 \pm 0.78$ & $3.20 \pm 0.67$ & $<0.001$ \\
\hline & $1.13 \pm 0.23$ & $1.10 \pm 0.22$ & $1.17 \pm 0.23$ & $<0.001$ \\
\hline \multirow{2}{*}{$\begin{array}{l}l \\
\text { rel }\end{array}$} & $2.34 \pm 0.48$ & $2.54 \pm 0.5$ & $2.15 \pm 0.36$ & $<0.001$ \\
\hline & $1.28 \pm 0.22$ & $1.23 \pm 0.21$ & $1.31 \pm 0.22$ & $<0.001$ \\
\hline \multirow{2}{*}{$l \cdot \mathrm{s}^{-1}$} & $8.17 \pm 2.61$ & $9.79 \pm 2.43$ & $6.62 \pm 1.65$ & $<0.001$ \\
\hline & $1.03 \pm 0.24$ & $1.08 \pm 0.24$ & $0.98 \pm 0.23$ & 0.003 \\
\hline \multirow[t]{2}{*}{$\mathrm{FEV}_{1}$} & $3.33 \pm 0.78$ & $3.75 \pm 0.75$ & $2.92 \pm 0.55$ & $<0.001$ \\
\hline & $1.00 \pm 0.14$ & $0.99 \pm 0.15$ & $1.02 \pm 0.14$ & NS \\
\hline \multirow[t]{2}{*}{$\mathrm{MEF}_{25}$} & $1.47 \pm 0.74$ & $1.64 \pm 0.80$ & $1.31 \pm 0.64$ & 0.001 \\
\hline & $0.74 \pm 0.31$ & $0.77 \pm 0.33$ & $0.71 \pm 0.29$ & NS \\
\hline \multirow{2}{*}{$\begin{array}{rr}\mathrm{MEF}_{50} & \begin{array}{l}l \cdot \mathrm{s}^{-1} \\
\text { rel. }\end{array}\end{array}$} & $3.83 \pm 1.37$ & $4.24 \pm 1.59$ & $3.44 \pm 0.99$ & $<0.001$ \\
\hline & $0.84 \pm 0.26$ & $0.85 \pm 0.29$ & $0.82 \pm 0.22$ & NS \\
\hline \multirow{2}{*}{$\begin{array}{cc}\mathrm{MEF}_{75} & \begin{array}{r}l \cdot \mathrm{s}^{-1} \\
\text { rel. }\end{array}\end{array}$} & $6.47 \pm 2.00$ & $7.44 \pm 2.1$ & $5.55 \pm 1.34$ & $<0.001$ \\
\hline & $0.94 \pm 0.22$ & $0.94 \pm 0.24$ & $0.94 \pm 0.21$ & NS \\
\hline \multirow{2}{*}{$\begin{array}{l}\mathrm{R}_{\text {osc }} \mathrm{kPa} \cdot \mathrm{s} \cdot l^{-1} \\
\mathrm{E}\end{array}$} & $0.36 \pm 0.12$ & $0.32 \pm 0.10$ & $0.39 \pm 0.13$ & $<0.001$ \\
\hline & $0.50 \pm 0.2$ & $0.52 \pm 0.13$ & $0.48 \pm 0.13$ & 0.02 \\
\hline $\mathrm{F}$ & $29.1 \pm 18$ & $27.4 \pm 17$ & $30.8 \pm 19$ & NS \\
\hline
\end{tabular}

Data are presented as mean \pm SD. PY: pack-yrs; VC: vital capacity; TLC: total lung capacity; FRC: functional residual capacity; $\mathrm{RV}$ : residual volume; PEF: peak expiratory flow; $\mathrm{FEV}_{1}$ : forced expiratory volume in one second; $\mathrm{MEF}_{25}, \mathrm{MEF}_{50}$ and $\mathrm{MEF}_{75}$ : maximal expiratory flow at 25, 50 and $75 \% \mathrm{VC} ; \mathrm{R}_{\mathrm{osc}}$ : oscillatory airway resistance; E: exponent which determines the curvature of the relationship between dispersion and volumetric lung depth; F: factor of the power function. p represents the significance level of the group difference between males and females (NS=not significant). Relative values (rel) are normalised to the reference value.

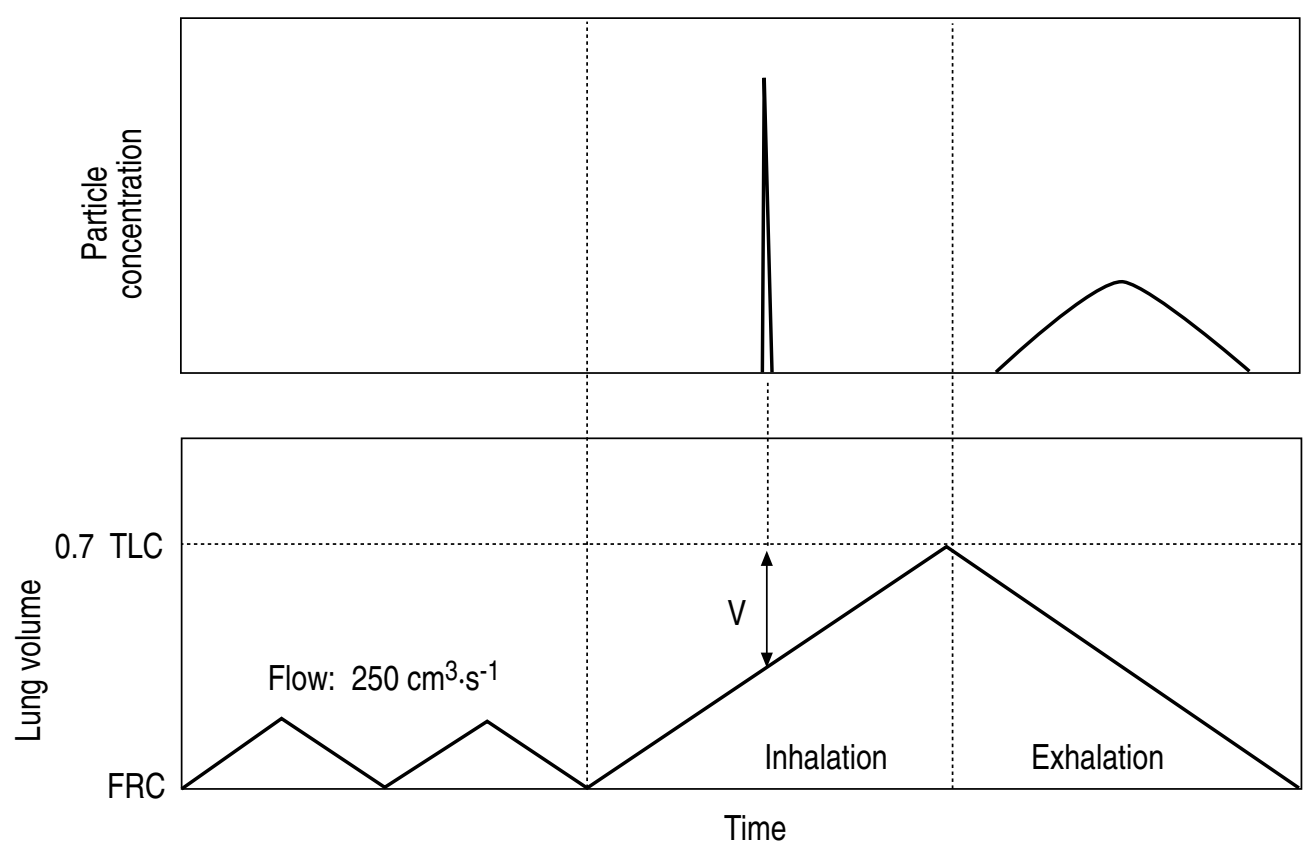

Fig. 3. - Depiction of the inhalation protocol. TLC: total lung capacity; FRC: functional residual capacity; V: volumetric lung depth. 
Table 2. - Ratio between the means of each parameter in smokers and in nonsmokers for data pooled and separated by sex

\begin{tabular}{lccc}
\hline $\begin{array}{c}\text { Smokers } \\
\text { to } \\
\text { nonsmokers }\end{array}$ & $\begin{array}{c}\text { Pooled } \\
\mathrm{n}=216\end{array}$ & $\begin{array}{c}\text { Males } \\
\mathrm{n}=106\end{array}$ & $\begin{array}{c}\text { Females } \\
\mathrm{n}=110\end{array}$ \\
\hline Age & 0.960 & 1.040 & 0.861 \\
& $(\mathrm{NS})$ & $(\mathrm{NS})$ & $(0.005)$ \\
Height & 1.021 & 1.002 & 1.006 \\
& $(0.006)$ & $(\mathrm{NS})$ & $(\mathrm{NS})$ \\
VC rel. & 0.992 & 1.010 & 0.987 \\
& $(\mathrm{NS})$ & $(\mathrm{NS})$ & $(\mathrm{NS})$ \\
TLC rel. & 0.980 & 1.004 & 0.981 \\
& $(\mathrm{NS})$ & $(\mathrm{NS})$ & $(\mathrm{NS})$ \\
FRC rel. & 0.957 & 0.989 & 0.946 \\
& $(\mathrm{NS})$ & $(\mathrm{NS})$ & $(\mathrm{NS})$ \\
$\mathrm{RV}_{\text {rel. }}$ & 0.978 & 0.990 & 0.992 \\
& $(\mathrm{NS})$ & $(\mathrm{NS})$ & $(\mathrm{NS})$ \\
PEF rel. & 1.000 & 0.957 & 1.007 \\
$\mathrm{FEV}_{1}$ rel. & $(\mathrm{NS})$ & $(\mathrm{NS})$ & $(\mathrm{NS})$ \\
& 0.943 & 0.946 & 0.946 \\
$\mathrm{MEF}_{25}$ rel. & $(0.003)$ & $(\mathrm{NS})$ & $(0.034)$ \\
$\mathrm{MEF}_{50}$ rel. & 0.886 & 0.794 & 1.093 \\
& $(0.039)$ & $(0.008)$ & $(0.005)$ \\
$\mathrm{MEF}_{75}$ rel. & 0.903 & 0.880 & 0.907 \\
& $(0.019)$ & $(0.049)$ & $(\mathrm{NS})$ \\
$\mathrm{R}_{\text {osc }}$ & 0.949 & 0.900 & 0.991 \\
$\mathrm{E}$ & $(\mathrm{NS})$ & $(\mathrm{NS})$ & $(\mathrm{NS})$ \\
& 1.031 & 1.006 & 1.112 \\
$\mathrm{~F}$ & $(\mathrm{NS})$ & $(\mathrm{NS})$ & $(\mathrm{NS})$ \\
& 1.194 & 1.207 & 1.159 \\
& $(<0.001)$ & $(<0.001)$ & $(0.003)$ \\
& 0.710 & 0.706 & 0.729 \\
& $(<0.001)$ & $(0.005)$ & $(0.008)$ \\
\hline
\end{tabular}

The significance level in brackets (p-value) indicates if the ratio is different from 1. Conventional lung function parameters are normalized to the reference value (rel.). For abbreviations see legend to table 1 .

and females. Although there are no significant differences in age between groups, all lung function parameters, except the relative values of $\mathrm{FEV}_{1}, \mathrm{MEF}_{25}, \mathrm{MEF}_{50}$, $\mathrm{MEF}_{75}$, and the factor $\mathrm{F}$ of aerosol dispersion, showed

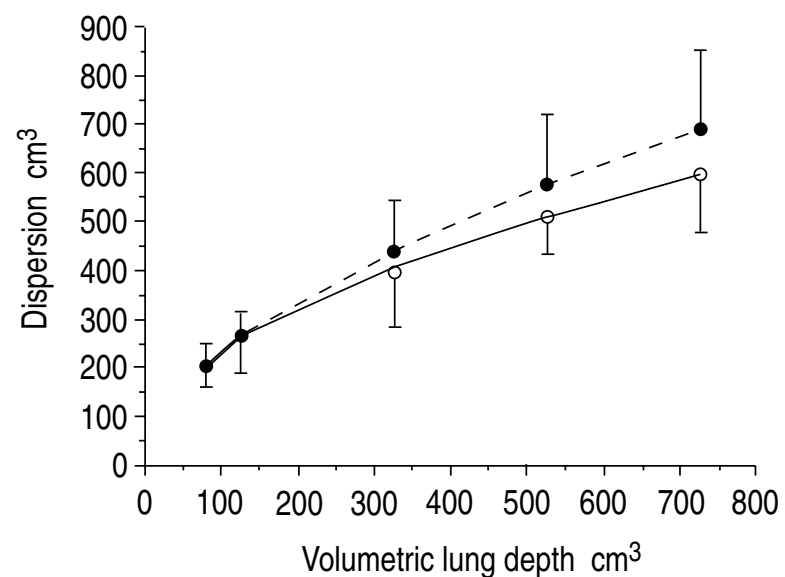

Fig. 4. - Aerosol bolus dispersion (mean $\pm \mathrm{SD}$ ) as a function of volumetric lung depth (V) measured in smokers and nonsmokers. - - : nonsmokers; $\longrightarrow$ : smokers.

significant $(\mathrm{p}<0.05)$ differences between sexes. Female smokers had smoked on average much fewer PY than males.

Table 2 shows the ratio between the mean of each parameter measured in smokers and the mean measured in nonsmokers for data pooled and separated by sex. The significance level $\mathrm{p}$ represents the probability that this ratio is equal to 1 . Since there are more smoking men (72) than women (54), smokers were on average significantly taller than nonsmokers. Smoking women were slightly younger than nonsmoking women, but for males and the pooled subjects no significant difference in age was observed. There were no significant differences in relative lung volumes, PEF and $\mathrm{MEF}_{75}$ between smokers and nonsmokers. FEV 1 was decreased in female smokers and all smokers, but the decrease was not significant in male smokers. $\mathrm{MEF}_{25}$ was decreased in male smokers and all smokers, but was significantly increased in females. $\mathrm{MEF}_{50}$ was decreased in male smokers and all smokers, but the decrease in female smokers was not significant. The aerosol bolus dispersion parameter $\mathrm{E}$ was significantly increased in all groups of smokers and $F$ was significantly decreased, which is due to increased bolus dispersion in smokers (fig. 4).

Table 3. - Significance levels for the dependence of various lung function and bolus dispersion parameters from anthropometric data and the cumulative cigarette consumption (package years)

\begin{tabular}{lccccc}
\hline Parameter & Sex & Age & Height & PY & $\begin{array}{c}\text { Slope } \\
\% / \text { PY }\end{array}$ \\
\hline VC rel. & NS & NS & NS & NS & \\
TLC rel. & 0.046 & 0.043 & NS & NS & \\
FRC rel. & 0.036 & NS & NS & NS & \\
RV rel. & NS & $<0.001$ & NS & NS & \\
PEF rel. & NS & NS & NS & NS & -0.3 \\
FEV $_{1}$ rel. & NS & NS & 0.03 & $<0.001$ & -0.7 \\
$\mathrm{MEF}_{25}$ rel. & 0.001 & $<0.001$ & NS & 0.006 & -0.6 \\
$\mathrm{MEF}_{50}$ rel. & 0.049 & 0.017 & NS & 0.005 & -0.5 \\
$\mathrm{MEF}_{75}$ rel. & NS & NS & NS & 0.002 & NS \\
$\mathrm{R}_{\text {osc }}$ & 0.047 & 0.002 & 0.011 & $<0.001$ & +0.6 \\
$\mathrm{~F}$ & $\mathrm{NS}$ & $\mathrm{NS}$ & $\mathrm{NS}$ & 0.001 & -1.3 \\
\hline
\end{tabular}

"Slope" represents the coefficient of PY in the linear regression model for each parameter normalized to its mean value. For abbreviations see legend to table 1. 

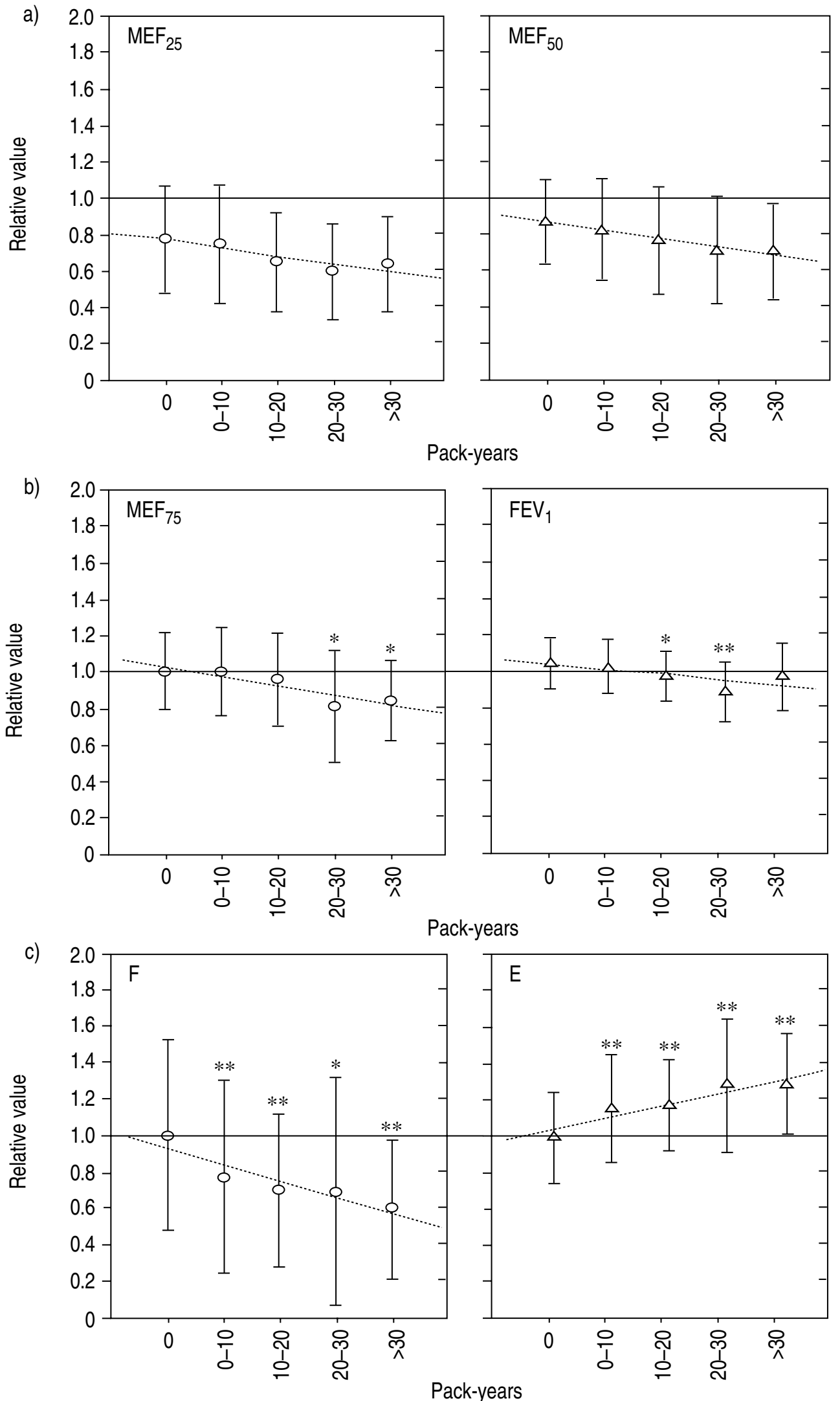

Fig. 5. - a) Mean \pm SD of a) maximal expiratory flow at 25 and $50 \%$ vital capacity $\left(\mathrm{MEF}_{25}\right.$ and $\left.\mathrm{MEF}_{50}\right)$ b) maximal expiratory flow at $75 \%$ vital capacity $\left(\mathrm{MEF}_{75}\right)$ and the forced expiratory volume in one second $\left(\mathrm{FEV}_{1}\right) \mathrm{c}$ ) factor $(\mathrm{F})$ and exponent $(\mathrm{E})$ of power functions fitted to the relationship between bolus dispersion and volumetric lung depth measured in classes of subjects with different cumulative cigarette consumption. Significant group differences between smokers of a class and nonsmokers $(\mathrm{PY}=0)$ are marked by asterisks. *: $\mathrm{p}<0.05 ; * *: \mathrm{p}<0.005$. The dotted line was fitted to the data by linear regression. 
In order to test whether the observed differences in lung function and bolus dispersion between smokers and nonsmokers are due to smoking and not caused by differences in anthropometric data, all parameters were studied by analysis of variance. Therefore, a linear model was assumed in which each parameter was supposed to be dependent on the anthropometric data, sex, age and height, and on the cumulative cigarette consumption PY. Table 3 shows that $\mathrm{FEV}_{1}, \mathrm{MEF}_{25}, \mathrm{MEF}_{50}, \mathrm{MEF}_{75}, \mathrm{~F}$ and $\mathrm{E}$ are significantly dependent on PY. All forced flow values decrease, $\mathrm{E}$ increases and $\mathrm{F}$ decreases with increasing PY.

To visualize this dependence on PY, smokers were classified into the following classes: $0<\mathrm{PY} \leq 10 \quad(\mathrm{n}=64)$; $10<\mathrm{PY} \leq 20(\mathrm{n}=32) ; 20<\mathrm{PY} \leq 30(\mathrm{n}=16) ;$ and $\mathrm{PY}>30$ $(n=14)$, and the mean and standard deviation of each parameter in the various classes of smokers are plotted in figs 5a-c. $\mathrm{FEV}_{1}, \mathrm{MEF}_{25}, \mathrm{MEF}_{50}$ and $\mathrm{MEF}_{75}$ of each subject were normalized to the reference value, and $E$ and $\mathrm{F}$ to the respective mean value in nonsmokers. Figure $5 \mathrm{a}$ and $\mathrm{b}$ show that $\mathrm{MEF}_{25}, \mathrm{MEF}_{50}, \mathrm{MEF}_{75}$ and $\mathrm{FEV}_{1}$ decrease with PY nearly linearly, but only $\mathrm{MEF}_{75}$ in smokers of more than $20 \mathrm{PY}$ and $\mathrm{FEV}_{1}$ in smokers

Table 4. - Probability $\left(\mathrm{p}_{\mathrm{ROC}}\right)$ that a randomly selected pair of smoker and nonsmoker is correctly ranked, calculated from the receiver operating characteristics (ROC)

\begin{tabular}{lcccc}
\hline Variable & Pooled & Males & Females & Healthy \\
\hline FEV $_{1}$ (rel.) & 0.62 & 0.62 & 0.61 & 0.51 \\
$\mathrm{MEF}_{25}$ (rel.) & 0.59 & 0.65 & 0.56 & 0.53 \\
$\mathrm{MEF}_{50}$ (rel.) & 0.61 & 0.65 & 0.59 & 0.58 \\
$\mathrm{MEF}_{75}$ (rel.) & 0.54 & 0.61 & 0.51 & 0.45 \\
$\mathrm{E}$ & 0.67 & 0.69 & 0.63 & 0.68 \\
$\mathrm{~F}$ & 0.68 & 0.70 & 0.66 & 0.71 \\
\hline
\end{tabular}

For abbreviations see legend to table 1 .

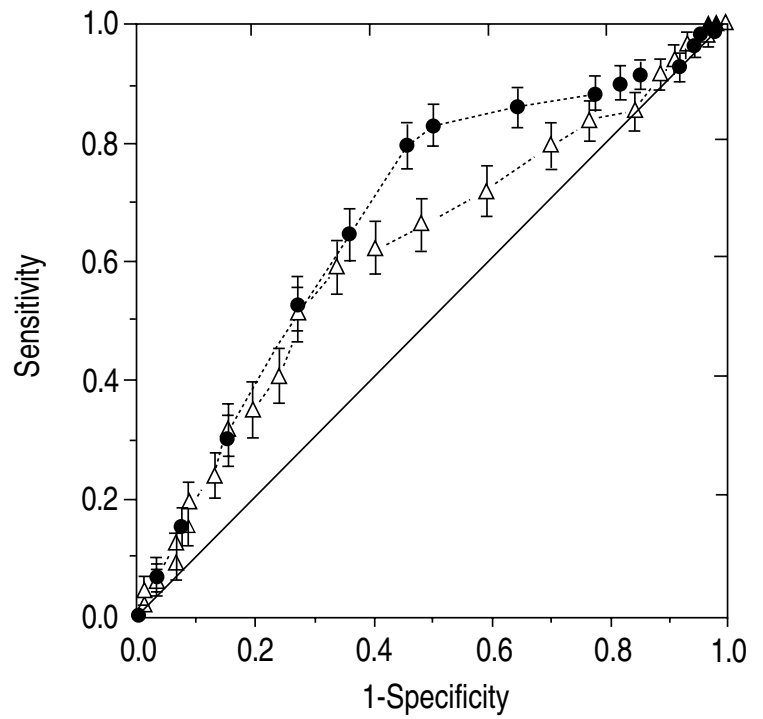

Fig. 6. - Relationship between sensitivity and specificity for the identification of smokers using the forced expiratory volume in one second $\left(\mathrm{FEV}_{1}\right)$ and the factor $(\mathrm{F})$ of power functions fitted to the relationship between bolus dispersion and volumetric lung depth. $\Delta$ : $\mathrm{FEV}_{1} ; \bullet$ ๑: $\mathrm{F}$ of $10<\mathrm{PY} \leq 30$ showed significant reductions in class mean values. Figure $5 \mathrm{c}$ shows the decrease of $\mathrm{F}$ and the increase of E with PY. In all classes of smokers, E and $F$ were significantly different from the mean value of nonsmokers.

Table 4 shows the probabilities $\left(\mathrm{P}_{\mathrm{ROC}}\right)$ calculated from the ROC of $\mathrm{FEV}_{1}, \mathrm{MEF}_{25}, \mathrm{MEF}_{50}, \mathrm{MEF}_{75}$, and the aerosol bolus dispersion parameters $\mathrm{F}$ and $\mathrm{E}$. The forced flow parameters had overall quite similar $\mathrm{p}_{\text {ROC }}$-values of about 0.6. Only $\mathrm{MEF}_{75}$ had, in all subpopulations, systematically lower $\mathrm{p}_{\mathrm{ROC}}$ than all other parameters. However, $\mathrm{E}$ and $\mathrm{F}$ had higher $\mathrm{p}_{\mathrm{ROC}}$ than parameters of conventional tests (0.67 in average). The ROC-curve for $\mathrm{FEV}_{1}$ and $\mathrm{F}$ for the pooled data is shown in figure 6 . For sensitivities lower than $60 \%$, both curves were almost identical but above this value, for a given value of specificity, $\mathrm{F}$ had an up to $20 \%$ higher sensitivity compared to $\mathrm{FEV}_{1}$.

\section{Discussion}

Of all lung function parameters under consideration, only $\mathrm{FEV}_{1}, \mathrm{MEF}_{25}, \mathrm{MEF}_{50}, \mathrm{MEF}_{75}$, and the dispersion parameters $\mathrm{E}$ and $\mathrm{F}$ were significantly changed in smokers. These parameters showed significant group differences between smokers and nonsmokers, as well as a dose response relationship with PY (fig. 5a-c). The flow parameters decreased with increasing PY. The slope of this decrease was highest for $\mathrm{MEF}_{25}$ and $\mathrm{MEF}_{50}$ (table 3 ), but due to a higher variability of these parameters (fig. 5a) none of the classes of smokers showed mean values significantly different from those of nonsmokers. FEV , had a lower slope of decrease with PY, but a much smaller standard deviation led to a significant decrease of this value for smokers of $10<\mathrm{PY} \leq 30$. Smokers of $\mathrm{PY}>30$ had no significant decrease in $\mathrm{FEV}_{1}$, presumably due to the smaller number of cases in this class. The observed decrease of the bolus dispersion parameter $\mathrm{F}$ in combination with an increase of $\mathrm{E}$ indicates that convective gas mixing is increased in the lungs of smokers. Again a dose response relationship with PY was found. The slope of this change was highest for F and nearly twice the maximum slope observed for parameters of spirometry. For all classes of smokers, even those with less than $10 \mathrm{PY}$, the observed increase of convective mixing was statistically significant.

These results show that early changes in lung function due to cigarette smoking can be detected with a higher sensitivity and specificity using the aerosol bolus dispersion technique than with conventional tests. This may be due to, at least, two different mechanisms. Either the information delivered by this technique is more or less equivalent to the information given by conventional tests but is assessed with a higher sensitivity, or aerosol bolus dispersion probes an aspect of lung function fundamentally different from that assessable with conventional tests. Looking at the pathophysiological mechanisms associated with smoking may help to identify the way aerosol bolus dispersion is changed in smokers.

Smoking induces inflammatory changes in small airways 
[17], which have been shown histologically [18]. The smoking-induced "respiratory bronchiolitis" is supposed to induce ventilatory inhomogeneities by changing local airway resistances or elastic properties of small airways. Ventilatory inhomogeneity in smokers has been shown by analysing the phase lag of the pressure flow relationship measured in a body plethysmograph [3], or the distribution of radioactive tracer gases in the lungs [19]. Inhomogeneous distribution of local airway resistances and elastic properties is equivalent to an inhomogeneous distribution of local ventilation time constants, which have been shown to have a strong influence on aerosol bolus dispersion in a simple simulation model [20]. It may, therefore, be postulated that the observed increase of bolus dispersion in smokers reflects altered mechanical properties of small airways caused by inflammatory processes due to smoking. The site of action associated with a changed aerosol bolus dispersion in smokers would then be localized in the lung periphery - the "silent zone" of the lungs, where conventional tests have their lowest sensitivity. The reason for this lack of sensitivity of conventional parameters is found in the fact that conventional tests are based, apart from the measurement of lung volumes, on the measurement of airway resistance, directly, or indirectly by measuring the forced flow volume curve. Since the total airway resistance is highly biased by the airway resistance of central airways [1, 2, 21, 22], these tests predominantly reflect properties of central airways. Only $\mathrm{MEF}_{50}$ and $\mathrm{MEF}_{25}$ are supposed to be influenced by the small airway dynamics [22], and indeed, these parameters have shown highest discriminatory power between smokers and nonsmokers.

The subjects in this study were randomly selected and, therefore, include persons with lung disease. Data of these persons were primarily included in the study, since the purpose of this investigation was to compare sensitivity and specificity of various lung function parameters. In a second step of the analysis, patients were excluded from the study population. The results of conventional lung function tests were examined by an experienced clinician to identify subjects with suspected lung disease. On the basis of the reference values proposed by the European Community for Coal and Steel, 67 subjects with abnormal lung function parameters were identified, 53 with suspected airway obstruction, 10 with suspected COPD and 4 with suspected lung restriction. In the remaining group of 149 subjects, ROC for the discrimination between smokers and nonsmokers were calculated. The $\mathrm{p}_{\mathrm{ROC}}$-values given in table 4 show a loss of sensitivity for the conventional lung function parameters, but a slight increase in sensitivity for aerosol bolus disperion parameters. The fact that change in composition of the study population markedly changes the discriminatory power of conventional parameters but does not alter that of aerosol bolus dispersion supports the hypothesis that aerosol bolus dispersion and conventional tests reflect fundamentally different aspects of lung function, and are hence complementary in their diagnostic capability. Aerosol bolus dispersion may have some benefit, particularly for the detection of early changes in the function of peripheral airways.

\section{Conclusions}

Early changes in lung function associated with cigarette smoking can be detected with the aerosol bolus dispersion technique with higher sensitivity and specificity than conventional lung function tests. The pathophysiological mechanisms associated with smoking suggest that the aerosol bolus dispersion technique delivers information from the lung periphery and is presumably influenced by inhomogeneous distributions of local airway resistances or elastic properties due to small airway inflammation. Since chronic inhalation of environmental air pollutants is supposed to induce lung injury similar to that observed in smokers, the aerosol dispersion technique might be a powerful tool of environmental epidemiology.

\section{References}

1. Wright JL, Cagle P, Churg A, Colby TV, Myers J. Diseases of the small airways. Am Rev Respir Dis 1992; 146: 240-262.

2. Chang HK. Flow dynamics in the respiratory tract. In: Change HK, Paiva M, eds. Respiratory Physiology. New York, Dekker, 1989.

3. Banerjee M, Evans JN, Jaeger MJ. Uneven ventilation in smokers. Respir Physiol 1976; 27: 277-291.

4. Anderson PJ, Blanchard JD, Brain JD, Feldman HA, McNamara JJ, Heyder J. Effect of cystic fibrosis on inhaled aerosol boluses. Am Rev Respir Dis 1989; 140: 1317-1324.

5. Rosenthal FS, Wright S. Assessment of papain-induced lung injury in isolated lungs: measurements of aerosol deposition and mixing. J Appl Physiol 1992; 72: 459467.

6. McCawley M, Lippmann M. Development of an aerosol dispersion test to detect early changes in lung function. Am Ind Hyg Assoc J 1988; 19: 81-89.

7. Keefe MJ, Bennett WD, Dewitt P, Seal E, Strong A, Gerrity T. The effect of ozone exposure on the dispersion of inhaled aerosol boluses in healthy human subjects. Am Rev Respir Dis 1991; 144: 23-30.

8. Alshuler B, Palmes ED, Yarmus L, Nelson N. Intrapulmonary mixing of gases studied with aerosol. J Appl Physiol 1959; 14: 321-327.

9. Heyder J, Davies CN. The breathing of half-micron aerosols. III. Dispersion of particles in the respiratory tract. J Aerosol Sci 1971; 2: 437-452.

10. Heyder J, Blanchard JD, Feldman HA, Brain JD. Convective mixing in the human respiratory tract: estimates with aerosol boli. J Appl Physiol 1988; 64: 12731278.

11. Ramm U, Rudolf G, Heyder J, Gebhart J. Studies of gas mixing in the human lung by means of aerosols. $J$ Aerosol Sci 1987; 18: 753-756.

12. Gebhart J, Heigwer G, Heyder J, Roth C, Stahlhofen W. The use of light scattering photometry in aerosol medicine. J Aerosol Med 1988; 1: 89-112.

13. Stahlhofen W, Armbruster L, Gebhart J, Grein E. Particle sizing of aerosols by single particle observation in a sedimentation cell. Atm Envir 1975; 9: 851-857.

14. Quanjer PH, Tammeling GJ, Cotes JE, Pedersen OF, Peslin R, Yernault JC. Lung volumes and forced ventilatory flows. Eur Respir J 1993; 6: 5-40. 
15. Metz CE. Basic principles of ROC analysis. Semin Nucl Med 1978; 8: 283-298.

16. Hanley JA, McNeil BJ. The meaning and use of the area under a receiver operating characteristic (ROC) curve. Radiology 1982; 143: 29-36.

17. Dockery DW, Speizer FE, Ferris BG, Ware JH, Louis TA, Spiro A. Cumulative and reversible effects of lifetime smoking on simple tests of lung function in adults. Am Rev Respir Dis 1988; 137: 286-292.

18. Niewoehner DE, Kleinerman J, Rice DB. Pathologic changes in the peripheral airways of young cigarette smokers. N Engl J Med 1974; 291: 755-758.

19. Barter SJ, Cunningham DA, Lavender JP, Gibellino F,
Connellan SJ, Pride NB. Abnormal ventilation scans in middle-aged smokers. Am Rev Respir Dis 1985; 132: 148-151.

20. Rosenthal FS. The effect of inhomogeneous ventilation on the dispersion of aerosol boluses: a model study. $J$ Aerosol Med 1993; 6: 68.

21. Hogg JC, Macklem PT, Thurlbeck WM, Path MC. Site and nature of airway obstruction in chronic obstructive lung disease. N Engl J Med 1968; 279: 1355-1360.

22. Wagner EM, Liu MC, Weinmann GG, Permutt S, Bleecker ER. Peripheral lung resistance in normal and asthmatic subjects. Am Rev Respir Dis 1990; 141: 584588 . 